University of Nebraska - Lincoln

DigitalCommons@University of Nebraska - Lincoln

Sociology Department, Faculty Publications

Sociology, Department of

2011

Age, Period, and Cohort Effects on Religious Activities and Beliefs

Philip Schwadel

University of Nebraska-Lincoln, pschwadel2@unl.edu

Follow this and additional works at: https://digitalcommons.unl.edu/sociologyfacpub

Part of the Sociology Commons

Schwadel, Philip, "Age, Period, and Cohort Effects on Religious Activities and Beliefs" (2011). Sociology Department, Faculty Publications. 176.

https://digitalcommons.unl.edu/sociologyfacpub/176

This Article is brought to you for free and open access by the Sociology, Department of at DigitalCommons@University of Nebraska - Lincoln. It has been accepted for inclusion in Sociology Department, Faculty Publications by an authorized administrator of DigitalCommons@University of Nebraska - Lincoln. 


\title{
Age, Period, and Cohort Effects on Religious Activities and Beliefs
}

\author{
Philip Schwadel, Department of Sociology, University of Nebraska-Lincoln, Lincoln, \\ Nebraska, USA; pschwadel2@unl.edu
}

\author{
Keywords: Religion; Age; Period; Cohort
}

Despite the theoretical emphasis on religious decline in modern societies, sociologists remain divided over trends in religious activity and belief that support or refute claims of religious decline. Much of this disagreement stems from the inability to distinguish between period and cohort effects when analyzing repeated cross-sectional survey data. I use the intrinsic estimator, a recently developed method of simultaneously estimating age, period, and cohort effects, to examine changes in Americans' religious service attendance, prayer, belief in the afterlife, and biblical literalism. Results show that regular service attendance declines, predominantly across cohorts. There are also period-and cohort-based declines in biblical literalism and a cohort-based decline in prayer. Belief in the afterlife is relatively stable across periods and cohorts. These results provide mixed support for theories of religious decline, and they demonstrate the importance of differentiating between period and cohort effects on social change.

\section{Introduction}

Sociological research on religion revolves around the notion of secularization or the decline of religion in modern societies. The view that religion is destined to decline in modernity can be traced back to the work of Comte, Weber, and Durkheim, among others, and it remains ingrained in modern sociology (Ruiter and van Tubergen, 2009; Wilson, 1982). Even theoretical approaches that emphasize the vitality of American religion, such as the religious economies perspective, are primarily arguing against secularization (e.g. Finke and Stark, 1992). Despite this focus on the decline of religion, or lack thereof, sociologists remain divided over trends in religious activity and belief that support or refute secularization claims (e.g. Chaves, 1989; Firebaugh and Harley, 1991; Greeley, 1989; Miller and Nakamura, 1996; Sasaki and Suzuki, 1987). Have key indicators of religious activity and belief declined over the last few decades and/or across birth cohorts, as individual-level secularization theories suggest? Or, have these indicators of religious vitality remained relatively stable over time and across birth cohorts, as opponents of secularization theories suggest?

In this article, I use a recently developed analysis technique to simultaneously estimate age, period, and birth cohort effects on regular religious service attendance, weekly prayer, belief in the afterlife, and biblical literalism. The linear dependency among age, period, and birth cohort creates modeling problems for age-period-cohort (APC) analyses (Firebaugh, 1997). This linear dependency leads researchers to make subjective choices in model constraint in order to estimate APC effects on religious activity and belief (Firebaugh and Harley, 1991). As I discuss below, APC intrinsic estimator models avoid the subjective assumptions inherent in previous APC analyses of religious activity and belief. I begin by summarizing the debate over religious decline in the United States, with particular attention to the role of birth cohorts in theories of religious change. Next, I discuss the central problems with previous APC analyses of religious belief and activity. I then describe the properties of APC intrinsic estimator models, which, unlike most other methods of simultaneously estimating age, period, and cohort effects, provide unbiased estimates of cohort and period effects (Yang et al., 2004). Using 1972-2006 General Social Survey data, I separately model age, period, and cohort effects on indicators of religious belief and activity with logistic regression models and simultaneously estimate age, period, and cohort effects on religiosity with APC intrinsic estimator models. I conclude by discussing the methodological and substantive significance of the findings.

Article history: received April 14, 2010; available online September 19, 2010.

Acknowledgments: The author thanks Jacob Cheadle, two anonymous reviewers, and the editor of Social Science Research for their comments on earlier drafts of this article. 
The Decline in Religion Thesis - Periods and/or Birth Cohorts

The term secularization encompasses a variety of expectations about the role of religion in modern societies, ranging from individual-level views of secularization that emphasize changes in people's religious perspectives and activities to more institutionally focused views of secularization that emphasize the declining influence of religion on social institutions, particularly the state (e.g. Chaves, 1994; Dobbelaere, 1999). The most prominent view of secularization is the "decline in religion thesis" (Swatos and Christiano, 1999, p. 215). This secularization perspective predicts that religious participation and belief decline as societies modernize (Norris and Inglehart, 2004; Voyé, 1995).

The decline in religion perspective suggests not only that religious activity and belief are declining but that religious practices and beliefs decline across birth cohorts (Chaves, 1989; Sasaki and Suzuki, 1987). Distinguishing between period and cohort effects is fundamental to understanding sources of social change, and religious change in particular. Social and cultural events often lead to period-based changes in outlook and activity. These changes affect people regardless of when they were born. Social change can also manifest across birth cohorts. Birth cohorts are characterized by socialization processes specific to their historical era, which often influence social change (Ryder, 1965). The religious beliefs and practices of Americans may change over time, reflecting a period effect, or across generations, reflecting a cohort effect. Specific events, such as the rise of the Christian Right, clergy sex-abuse scandals, or the Scopes Trial, can lead to period-based changes in religious practice and belief. Conversely, differences in socialization across birth cohorts may lead to cohort-based changes in religious activities and beliefs. Theories of religious change tend to predict declines in religious practice and belief across birth cohorts due to cohort differences in culture, education, geographic mobility, urbanization, and various other attributes that influence religion (e.g. Carroll et al., 1979; Chaves, 1989; Roof and McKinney, 1987; Sasaki and Suzuki, 1987; Wuthnow, 1976).

In addition to the theoretical expectation of cohort changes in religious belief and practice, there are important methodological reasons to account for cohort effects when analyzing trends in religious belief and activity. Failure to address changes across birth cohorts can result in misleading time trends. In particular, apparent changes over time may be underestimated or exaggerated due to the relative age of specific birth cohorts. The baby boom generation provides two relevant examples. First, the large baby boom generation coupled with greater religious participation during childhood led to growth in religious activity in the 1950s and 1960s, when baby boomers were children, and religious decline in the 1970s, when baby boomers were young adults (Carroll et al., 1979). Second, the disproportionately large baby boom generation may now be concealing a decline in religious participation over time because baby boomers participate more frequently as they age, thereby increasing overall participation (Miller and Nakamura, 1996). To account for potential misleading results due to the conflation between period and cohort, a thorough analysis of changes in religious activity and belief must simultaneously examine cohort and period effects.

Methodological Problems with Age-Period-Cohort Analyses of Religious Belief and Activity

Attempts to distinguish between cohort and period effects using repeated cross-sectional survey data have been hampered by the linear dependency among age, period (i.e. survey year), and birth cohort. Specifically, period $=$ age + cohort. Cohort effects cannot be reliably estimated without including age in the model; and age, period, and cohort cannot be simultaneously modeled using standard regression techniques due to their linear dependency. This linear dependency, or the "identification problem" as it is referred to in the APC literature (Firebaugh, 1997), has prevented researchers from establishing the relative impact of age, period, and cohort on religious activities and beliefs. Although there is as of yet no solution to the identification problem, various strategies have been used in attempts to overcome the linear dependency among age, period, and cohort. ${ }^{1}$

In analyses of religious activity and belief, the two principal methods of overcoming the identification problem are making "identifying assumptions" and dropping key indicators from the model (Firebaugh, 1997; Firebaugh and Harley, 1991). The primary indentifying assumption involves constraining the effects of adjacent cohorts, age groups, or periods to be equal in an attempt to reduce collinearity (e.g. Hout and Greeley, 1987). This method, however, still leaves "a high degree of collinearity among the three variables" (Firebaugh, 1997, p. 10), and is particularly problematic in analyses of religious activity (Ploch and Hastings, 1994). The other frequently used method of overcoming the identification problem in analyses of religious change is to include only two of the three measures - age, period, or cohort - in a regression model (e.g. Chaves, 1989). Unfortunately, the effects of age, period, or cohort may still be biased by the impact of the absent variable (Firebaugh and Harley, 1991). Methods of avoiding the identification problem rely primarily on subjective choices of model constraint. These subjective choices can lead to divergent and even conflicting estimates depending on the assumptions made (Fu, 2008).

${ }^{1} \mathrm{See} \mathrm{Fu}(2008)$ for a summary of the debate over whether an estimable function for overcoming the identification problem exists. 
Because researchers make subjective choices in model constraint, different attempts to avoid the identification problem in APC analyses of religious activity and belief have led to considerably different conclusions about cohort and period effects on religion (Firebaugh and Harley, 1991). Chaves (1989), for example, uses a model without age to conclude that Protestants' religious participation declines across cohorts. In contrast, Firebaugh and Harley (1991, p. 488) argue that the cohort changes identified by Chaves reflect "lifecycle effects repeated in one birth cohort after another." Similarly, Greeley (1989, p. 54) reports that "there is no cohort effect on American church attendance" while Miller and Nakamura (1996, p. 282) find that "Post-WWII cohorts attend church far less frequently than their predecessors." Methodological problems with APC models continually lead to disagreements between those who say religious activity declines across birth cohorts (e.g. Chaves, 1991; Sasaki and Suzu$\mathrm{ki}, 1987$ ) and those who assert there are no cohort effects on religious activity (e.g. Hout and Greeley, 1987).

The Intrinsic Estimator: A New Technique for Estimating Age, Period, and Cohort Effects

Recent advances in modeling APC effects with repeated cross-sectional data allow age, period, and cohort effects to be simultaneously estimated without making subjective choices requiring constraining data or dropping age, period, or cohort indicators from the model. In particular, APC intrinsic estimator models provide unbiased estimates of regression coefficients for age groups, time periods, and birth cohorts (Fu, 2000). The bias imposed by the arbitrary constraints associated with other methods of modeling APC effects is especially problematic when there are relatively few periods. APC intrinsic estimator models, on the other hand, produce unbiased estimates with few time periods (Yang et al., 2004). Most methods of simultaneously estimating age, period, and cohort effects are influenced by the design matrix (i.e. number of time periods in the analysis). "The basic idea of the IE," note Yang et al. (2008, p. 1,707), "is to remove the influence of the design matrix on coefficient estimates."

Unlike other methods of estimating APC effects that rely on constraints imposed subjectively by the investigator, APC intrinsic estimator models provide "estimable functions that are invariant to the selection of constraints on the parameters" (Yang et al., 2004, p. 77). The intrinsic estimator does place special constraints on model parameters, but these constraints are unrelated to the investigator's knowledge of the subject (Fu, 2008). These constraints are also unrelated to the variables in the model. Another benefit of APC intrinsic estimator models is that they are more statistically efficient than methods that constrain data to avoid the identification problem (Yang et al., 2008). Most importantly, APC intrinsic estimator models meet Glenn's (2005) criteria for an acceptable, general-purpose method of simultaneously estimating age, period, and cohort effects (Yang et al., 2008). In the following analysis, I use intrinsic estimator models to estimate age, period, and cohort effects on regular religious service participation, weekly prayer, belief in the afterlife, and biblical literalism.

Data and Methods

I use data from the 1972-2006 General Social Survey (GSS) to examine changes in religious activities and beliefs. The GSS surveys a random sample of non-institutionalized, American adults annually or biennially (Davis et al., 2007). The GSS is primarily administered in-person though some interviews are completed over the phone. Response rates range between 0.70 and $0.80 .^{2}$

Since the dependent variables are not each included in all years of the survey, the sample size varies across models from 21,741 to 49,467. All analyses are weighted to adjust for the sub-sampling of non-respondents as well as variations in the number of adults per household and other sampling variations. ${ }^{3}$ Independent variables measure age, period, and birth cohort. Age, period, and cohort variables are coded into roughly 5 -year intervals. ${ }^{4}$ Since my goal is to identify period and cohort changes rather than causes of change in religious activity and belief across periods or cohorts, the models do not contain any control variables.

\footnotetext{
${ }^{2}$ Response rates based on Response Rate 5 as defined by the American Association for Public Opinion Research (2008). See GSS Appendix A for more information on sampling and response rates.

${ }^{3}$ There is little difference in results between weighted and unweighted intrinsic estimator models.

${ }^{4}$ Although the choice of intervals is somewhat arbitrary, 5-year intervals are the norm in age-period-cohort analyses (Yang et al., 2008). Thus, age and period are coded into 5-year intervals. The diagonal aspects of the age by period matrix represent birth cohorts. Following Yang et al. (2008), I group respondents 75 years old or older into a single age category for more stable estimates. There are two other exceptions to the 5-year interval guideline: 1972 through 1974 is coded as a single period even though it only covers three years and the 2006 survey is combined with the 2000 through 2004 surveys into a single period. Respondents below 20 years old are deleted from the sample.
} 


\section{Dependent Variables}

All four dependent variables are dichotomous. The first two dependent variables - religious service attendance and prayer - measure religious activity. These variables capture the most common form of institutional religious activity (religious service attendance) and a basic form of individual religious activity (prayer). The prayer variable compares respondents who pray weekly (78 percent) to those who pray less than weekly ( 23 percent). The religious service attendance variable compares respondents who attend at least 2-3 times a month (43 percent) to those who attend less often (57 percent). Both variables are dichotomized from ordinal variables. Although using dichotomous measures of religious activity is a common practice in cohort analyses (e.g. Chaves, 1989; Sasaki and Suzuki, 1987; Wuthnow, 1976), it is not ideal. Unfortunately, the ordinal measures of frequency of religious service attendance and prayer are not appropriate for this analysis since there is no ordered response intrinsic estimator model. Alternative models treating the ordinal measures of service attendance and prayer as continuous variables show similar patterns to those presented below.

The other two dependent variables - belief in the afterlife and biblical literalism - measure religious belief. While these two variables do not encompass the totality of mainstream religious beliefs in the United States, biblical literalism taps the core belief of evangelical or conservative Christianity (Marsden, 1991) and belief in the afterlife is a standard belief across major religious traditions in the United States (Greeley and Hout, 1999). Belief in the afterlife is coded zero for those who do not believe in life after death (20 percent) and one for those who believe in life after death (80 percent). The GSS biblical literalism question has four response categories: the bible is the actual word of God and is to be taken literally, word for word; the bible is the inspired word of God but not everything in it should be taken literally, word for word; the bible is an ancient book of fables, legends, history, and moral precepts recorded by men; and other views of the bible. Biblical literalism is recoded into a dichotomous variable comparing belief that the bible is the actual word of God (34 percent) with all other responses (66 percent).

\section{Analysis Technique}

The first part of the analysis establishes gross age, period, and cohort effects on religious activities (weekly prayer and regular religious service attendance) and religious beliefs (biblical literalism and belief in the afterlife). I use binary logistic regression models to separately estimate the effects of age, period, and cohort for each of the dependent variables. Each binary logistic regression model includes dummy variables for age categories, periods, or birth cohorts. Consequently, the logistic regression results represent age effects without controlling for cohort or period, period effects without controlling for age or cohort, and cohort effects without controlling for age or period. There are no constants in the logistic regression models. Results from the binary logistic regression models are shown in Figure 1. Tables containing the logistic regression results are omitted to save space (available on request). The second part of the analysis examines net age, period, and cohort effects on religious activity and belief. Intrinsic estimator models are used to simultaneously estimate APC effects. The intrinsic estimator is a special form of principal components regression estimator that adjusts for the linear dependency among age, period, and cohort through singular value decomposition of matrices (Yang et al., 2004, 2008). As noted above, the intrinsic estimator provides unbiased estimates of age, period, and cohort effects. While the intrinsic estimator places special constraints on model parameters, these constraints are unrelated to decisions made by the researcher (Fu, 2008). Intrinsic estimator models appear to provide more methodologically accurate (Yang et al., 2008) and theoretically appropriate (Schwadel, 2010a) results than other methods of simultaneously estimating APC effects (see Yang et al. (2008) for a detailed discussion of the properties of the intrinsic estimator). A logit link function is used to adjust for the dichotomous outcomes. For ease of interpretation, all results are graphed as probabilities.

\section{Results}

Gross Age, Period, and Cohort Effects

I begin with analyses of gross age, period, and cohort effects on religious activity and belief. Results from binary logistic regression models of regular religious service attendance, weekly prayer, biblical literalism, and belief in the afterlife are shown in Figure 1. As noted above, these results are based on separate age, period, and cohort regressions for each of the four dependent variables (i.e. 12 regression models). Figure 1a reveals that three of the four religion indicators are positively associated with age. Older respondents are disproportionately likely to regularly attend religious services, to pray weekly, and to believe the bible is the literal word of God. Age has little association with belief in the afterlife. Figure $1 \mathrm{~b}$ shows moderate declines in attendance and biblical literalism across time periods. Conversely, Belief in the afterlife increases from 1972 to 2006. Prayer does not change much across periods. Figure 1c suggests large cohort differences. Prayer, attendance, and biblical literalism decline considerably across cohorts while belief in the afterlife is most common among the oldest and youngest co- 
horts. The period and cohort trends in religious activity and belief reported in Figure 1 suggest both religious decline and religious stability. The probability of biblical literalism and regular religious service attendance both declined across periods. Attendance and biblical literalism also declined across birth cohorts, as did prayer. Of course, these cohort changes may reflect age differences since attendance, biblical literalism, and prayer are all strongly associated with age. In contrast to biblical literalism and service attendance, belief in the afterlife increased moderately across time periods and frequency of prayer was stable across periods. The period effects, however, may be influenced by the age composition of specific birth cohorts since unmeasured cohort effects can suppress time trends (Miller and Nakamura, 1996). Age, period, and cohort effects must be simultaneously modeled to ensure that cohort effects do not reflect unmeasured age effects and that period effects are not unduly influenced by the age of specific cohorts.
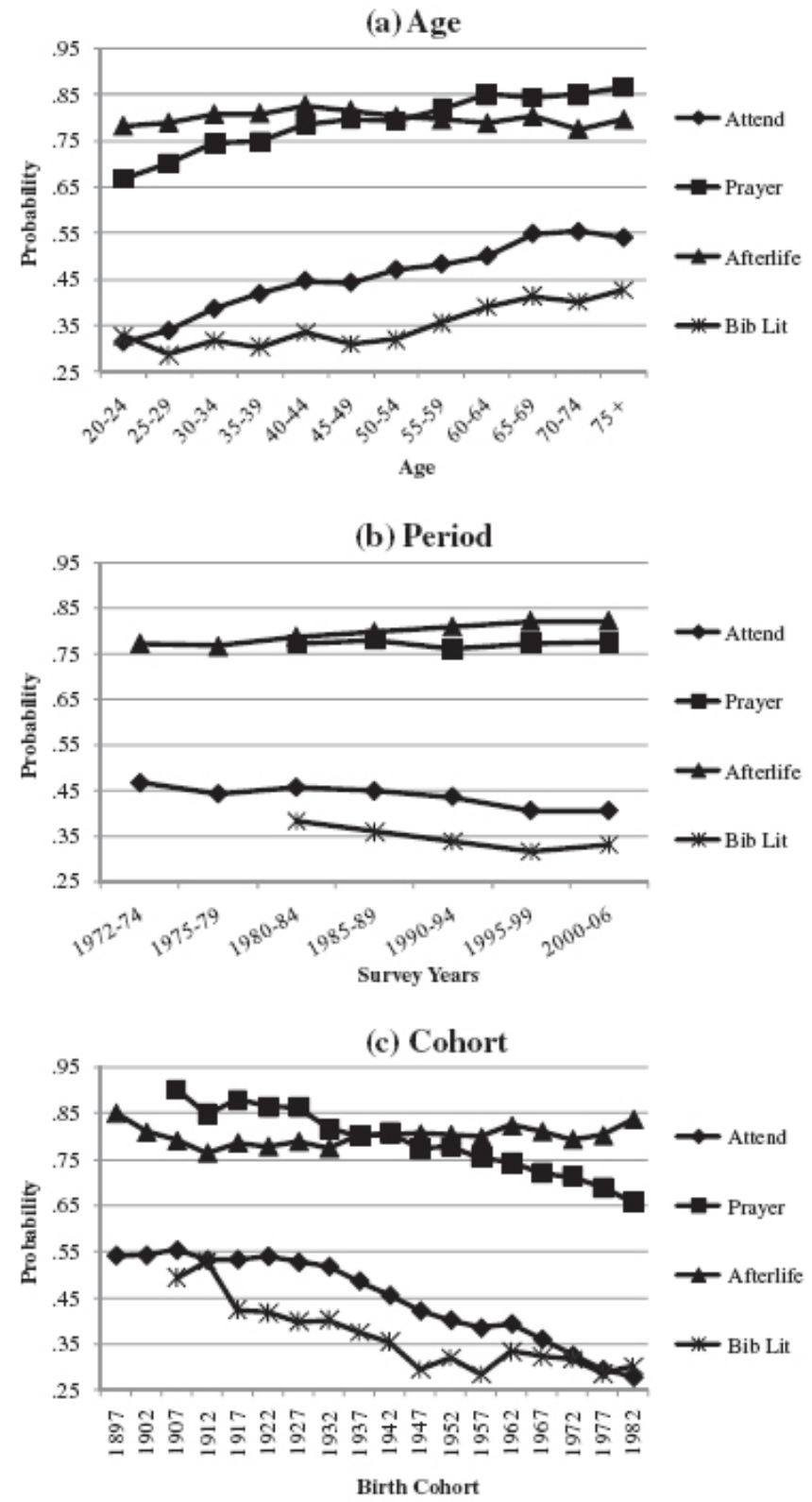

Figure 1. Gross age, period, and cohort effects on regular service attendance, weekly prayer, belief in the afterlife, and biblical literalism. Notes: Figure graphs results from binary logistic regressions with no constant; each line represents a separate model (i.e. age, period, and cohort effects modeled independently). 
Table 1 Age-period-cohort intrinsic estimator models of regular religious service attendance and weekly prayer.

\begin{tabular}{|c|c|c|c|c|}
\hline & \multicolumn{2}{|c|}{ Service attendance } & \multicolumn{2}{|c|}{ Prayer } \\
\hline & $\beta$ & SE & $\beta$ & SE \\
\hline \multicolumn{5}{|l|}{$\overline{A g e}$} \\
\hline $20-24$ & -0.45 & $0.04^{* * *}$ & -0.61 & $0.07^{* * *}$ \\
\hline $25-29$ & -0.36 & $0.03^{* * *}$ & -0.46 & $0.06^{* * *}$ \\
\hline $30-34$ & -0.17 & $0.03^{* * *}$ & -0.25 & $0.05^{* * *}$ \\
\hline $35-39$ & -0.06 & $0.03^{*}$ & -0.20 & $0.05^{* * *}$ \\
\hline $40-44$ & 0.02 & 0.03 & 0.03 & 0.06 \\
\hline $45-49$ & -0.02 & 0.03 & 0.13 & 0.07 \\
\hline $50-54$ & 0.05 & 0.04 & 0.08 & $0.07^{*}$ \\
\hline $55-59$ & 0.06 & 0.04 & 0.25 & $0.08^{* * *}$ \\
\hline $60-64$ & 0.10 & $0.04^{* *}$ & 0.34 & $0.08^{* * *}$ \\
\hline $65-69$ & 0.28 & $0.04^{* * *}$ & 0.22 & $0.09^{* * *}$ \\
\hline $70-74$ & 0.29 & $0.04^{* * *}$ & 0.22 & $0.09^{* * *}$ \\
\hline $75+$ & 0.25 & $0.04^{* * *}$ & 0.24 & $0.09 * * *$ \\
\hline \multicolumn{5}{|l|}{ Period } \\
\hline $1972-1974$ & 0.06 & $0.03^{*}$ & & \\
\hline 1975-1979 & -0.01 & 0.03 & & \\
\hline 1980-1984 & 0.07 & $0.03^{* *}$ & 0.00 & 0.04 \\
\hline 1985-1989 & 0.04 & 0.02 & 0.05 & 0.03 \\
\hline 1990-1994 & 0.01 & 0.02 & -0.09 & $0.04^{* *}$ \\
\hline 1995-1999 & -0.09 & $0.03^{* *}$ & 0.01 & 0.05 \\
\hline 2000-2006 & -0.08 & $0.02^{* * *}$ & 0.02 & $0.04^{*}$ \\
\hline \multicolumn{5}{|l|}{ Cohort } \\
\hline 1897 & 0.05 & 0.13 & & \\
\hline 1902 & 0.08 & 0.08 & & \\
\hline 1907 & 0.10 & 0.07 & 0.58 & $0.23^{* * *}$ \\
\hline 1912 & 0.06 & 0.06 & 0.06 & 0.14 \\
\hline 1917 & 0.10 & $0.05^{*}$ & 0.37 & $0.12^{* * *}$ \\
\hline 1922 & 0.18 & $0.05^{* * *}$ & 0.20 & $0.11^{* *}$ \\
\hline 1927 & 0.17 & $0.04^{* * *}$ & 0.17 & 0.09 \\
\hline 1932 & 0.16 & $0.04^{* * *}$ & -0.14 & 0.09 \\
\hline 1937 & 0.07 & 0.04 & -0.19 & $0.09 *$ \\
\hline 1942 & 0.01 & 0.04 & -0.13 & $0.08^{*}$ \\
\hline 1947 & -0.06 & 0.04 & -0.25 & $0.07^{* * *}$ \\
\hline 1952 & -0.08 & $0.03^{*}$ & -0.09 & $0.06^{* *}$ \\
\hline 1957 & -0.10 & $0.03^{* *}$ & -0.14 & $0.06^{* * *}$ \\
\hline 1962 & -0.04 & 0.03 & -0.05 & 0.05 \\
\hline 1967 & -0.10 & $0.04^{* *}$ & -0.06 & $0.06^{*}$ \\
\hline 1972 & -0.18 & $0.05^{* * *}$ & -0.07 & 0.07 \\
\hline 1977 & -0.20 & $0.06^{* * *}$ & -0.12 & 0.09 \\
\hline 1982 & -0.22 & $0.09^{*}$ & -0.15 & 0.12 \\
\hline Intercept & \multirow{2}{*}{\multicolumn{2}{|c|}{49,467}} & 1.39 & $0.03^{* * *}$ \\
\hline$N$ & & & \multicolumn{2}{|c|}{21,741} \\
\hline
\end{tabular}

${ }^{*} p \leq 0.05,{ }^{* *} p \leq 0.01,{ }^{* * *} p \leq 0.001$ (two-tailed test).

Net Age, Period, and Cohort Effects

Table 1 reports results from APC intrinsic estimator models of regular religious service attendance and weekly prayer. These results are graphed in Figure 2 (attendance) and Figure 3 (prayer). Age has a strong, positive effect on religious service attendance. The positive association between age and service attendance suggests that cohort effects estimated from models of attendance that do not include age may partially reflect lifecycle effects (Firebaugh and Harley, 1991). Even after controlling for age, however, there is a decline in service attendance across cohorts. As Figure 2c shows, the probability of regular attendance reaches a high of about 0.5 for the 1922-1932 birth cohorts and a low of about 0.4 for the 1972-1982 birth cohorts. The across-cohort decline in attendance coupled with the positive effect of age on attendance suggests that the disproportionately large baby boomer generation may indeed be inflating attendance rates as they age (Miller and Nakamura, 1996). There is also a period-based decline in regular attendance, though the period changes are far smaller than the changes across cohorts. The probability of regular attendance is moderately lower in the final two time periods (1995-2006) than in earlier periods. 
(a) Age

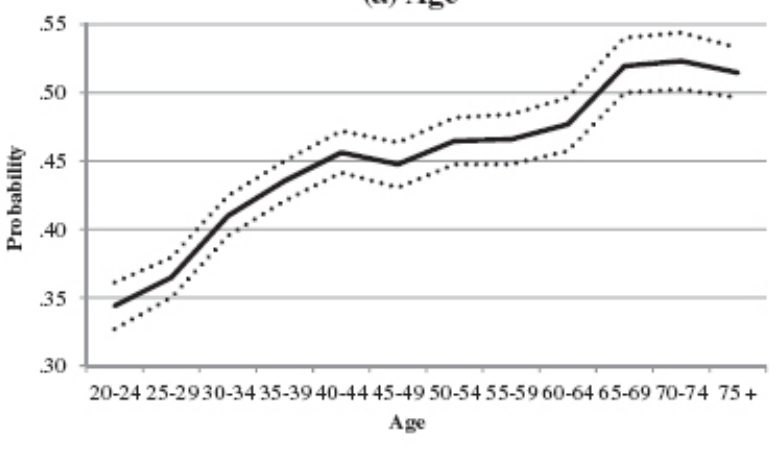

(b) Period

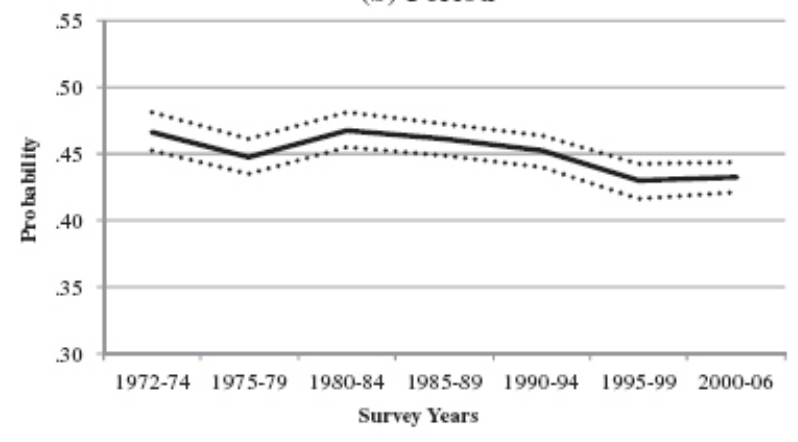

(c) Cohort

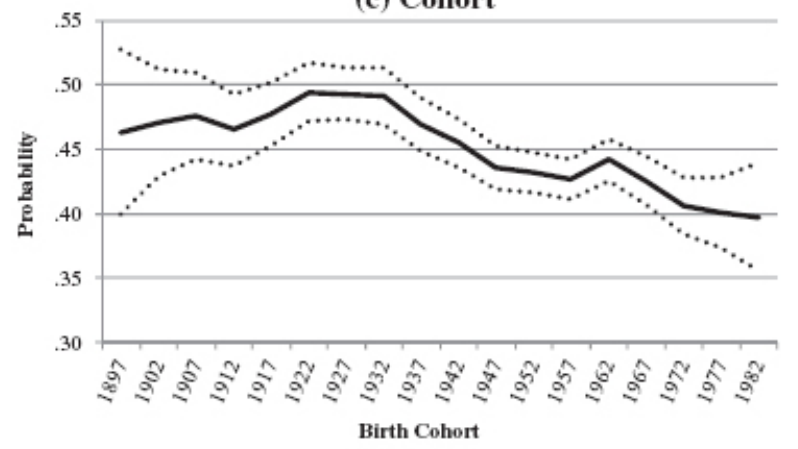

Figure 2. Estimated age, period, and cohort effects on probability of regular religious service attendance. Notes: Figure graphs results reported in Table 1; dashed lines represent 95 percent confidence intervals.

A similar pattern emerges with weekly prayer. Although there is no gross decline in prayer over time (Figure 1) and there is little net period-based variation in prayer (Table 1 and Figure $3 b$ ), there is a notable decline in prayer across cohorts (Table 1 and Figure 3c). Weekly prayer is particularly common among cohorts born before the 1930s. The probability of weekly prayer is above 0.8 for each pre-1930s cohort and below 0.8 for each cohort born since the 1930s. Together, the positive effect of age on prayer and the across-cohort decline in prayer suggest that cohort replacement may eventually lead to declines in weekly prayer despite the apparent stability of prayer over time.

Results from APC intrinsic estimator models of biblical literalism and belief in the afterlife are reported in Table 2 and depicted in Figure 4 (afterlife) and Figure 5 (biblical literalism). The results show only modest age, period, and cohort effects on belief in the afterlife. Respondents in their 20 s are relatively unlikely to believe in the afterlife (probabilities still above 0.76) and those in their forties are disproportionately likely to believe in the afterlife. There are no other significant differences among age groups. Other than lower than average levels of belief in the afterlife in the 1975-1979 period and higher than average levels of belief in the 1995-1999 period, there are no 
(a) Age

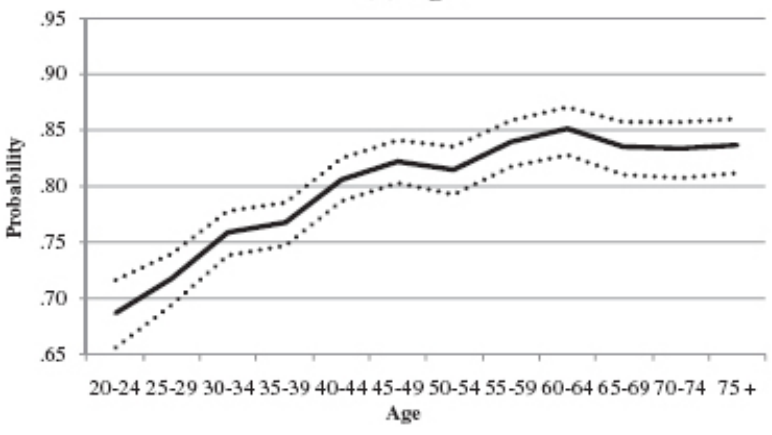

(b) Period

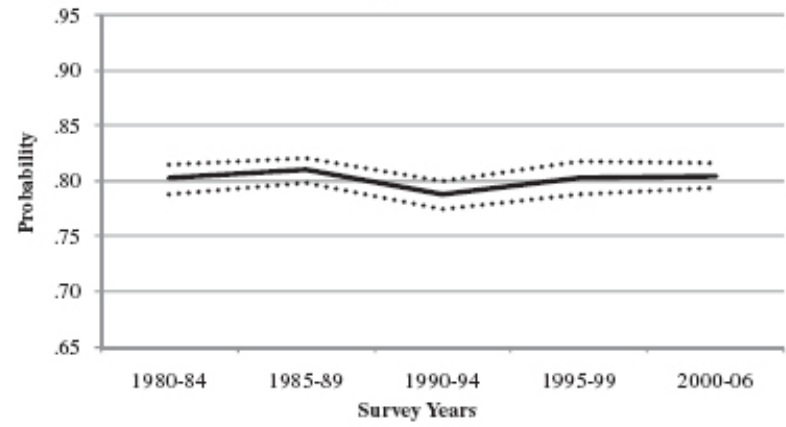

(c) Cohort

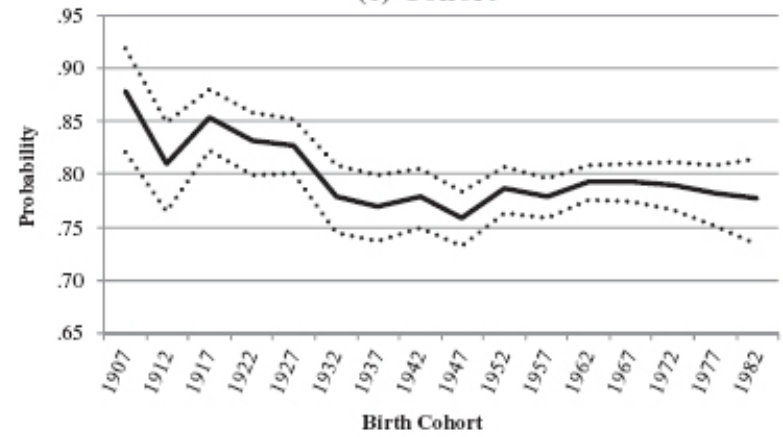

Figure 3. Estimated age, period, and cohort effects on probability of weekly prayer. Notes: Figure graphs results reported in Table 1; dashed lines represent 95 percent confidence intervals.

notable period-based changes. The cohort effects are also relatively small. The youngest cohort is particularly likely to believe in the afterlife while the 1912, 1922, and 1932 cohorts are particularly unlikely to believe in the afterlife. Although the oldest cohorts appear disproportionately likely to report belief in the afterlife, estimates for the oldest cohorts are not stable, as evident by the large confidence intervals (Figure 4c). The mostly insignificant age, period, and cohort effects on belief in the afterlife support research that suggests that belief in the afterlife remains high over time and across various social groups (e.g. Greeley and Hout, 1999).

The final dependent variable, biblical literalism, varies by age, period, and birth cohort (Table 2 and Figure 5). Odds of viewing the bible as the literal word of God is positively associated with age. The probability of biblical literalism increases from about 0.3 in the late 20 s to 0.4 for those 60 or older. There is a notable period-based decline in biblical literalism. The probability of biblical literalism decreases from 0.4 in the 1980-1984 period to about 0.35 in the last two time periods. There are also cohort-based changes in biblical literalism. The oldest birth cohorts, especially the 1912 cohort, are disproportionately likely to view the bible as the literal word of God. The post-World War II cohorts, born in the latter half of the 1940s and in the 1950s, are particularly unlikely to be 
Table 2 Age-period-cohort intrinsic estimator models of belief in the afterlife and biblical literalism.

\begin{tabular}{|c|c|c|c|c|}
\hline & \multicolumn{2}{|c|}{ Afterlife } & \multicolumn{2}{|c|}{ Biblical literalism } \\
\hline & $\beta$ & SE & $\beta$ & SE \\
\hline \multicolumn{5}{|l|}{$\overline{A g e}$} \\
\hline $20-24$ & -0.25 & $0.07^{* * *}$ & -0.13 & 0.07 \\
\hline $25-29$ & -0.14 & $0.06^{*}$ & -0.34 & $0.06^{* * *}$ \\
\hline $30-34$ & -0.01 & 0.05 & -0.15 & $0.05^{* *}$ \\
\hline $35-39$ & -0.01 & 0.05 & -0.17 & $0.05^{* * *}$ \\
\hline $40-44$ & 0.13 & $0.05^{*}$ & 0.03 & 0.05 \\
\hline $45-49$ & 0.12 & $0.06^{*}$ & -0.01 & 0.06 \\
\hline $50-54$ & 0.06 & 0.06 & -0.04 & 0.06 \\
\hline $55-59$ & 0.05 & 0.06 & 0.13 & $0.07 *$ \\
\hline $60-64$ & 0.01 & 0.06 & 0.16 & $0.07^{*}$ \\
\hline $65-69$ & 0.12 & 0.07 & 0.21 & $0.07^{* *}$ \\
\hline $70-74$ & -0.07 & 0.07 & 0.12 & 0.07 \\
\hline $75+$ & -0.01 & 0.07 & 0.17 & $0.07^{* *}$ \\
\hline \multicolumn{5}{|l|}{ Period } \\
\hline $1972-1974$ & -0.10 & 0.06 & & \\
\hline $1975-1979$ & -0.14 & $0.04^{* * *}$ & & \\
\hline $1980-1984$ & -0.03 & 0.04 & 0.16 & $0.06^{* *}$ \\
\hline $1985-1989$ & 0.01 & 0.04 & 0.05 & 0.04 \\
\hline 1990-1994 & 0.06 & 0.04 & -0.02 & 0.03 \\
\hline 1995-1999 & 0.12 & $0.05^{\star * *}$ & -0.12 & $0.03^{* * *}$ \\
\hline $2000-2006$ & 0.08 & 0.04 & -0.06 & 0.03 \\
\hline \multicolumn{5}{|l|}{ Cohort } \\
\hline 1897 & 0.43 & 0.42 & & \\
\hline 1902 & 0.17 & 0.16 & & \\
\hline 1907 & 0.00 & 0.13 & 0.20 & 0.24 \\
\hline 1912 & -0.21 & $0.11^{*}$ & 0.44 & $0.12^{* * *}$ \\
\hline 1917 & -0.11 & 0.10 & 0.07 & 0.09 \\
\hline 1922 & -0.19 & $0.09^{*}$ & 0.06 & 0.08 \\
\hline 1927 & -0.14 & 0.08 & 0.00 & 0.07 \\
\hline 1932 & -0.24 & $0.08^{* *}$ & 0.04 & 0.08 \\
\hline 1937 & -0.10 & 0.08 & -0.04 & 0.08 \\
\hline 1942 & -0.08 & 0.07 & -0.08 & 0.07 \\
\hline 1947 & -0.06 & 0.06 & -0.32 & $0.07^{* * *}$ \\
\hline 1952 & -0.02 & 0.05 & -0.12 & 0.06 \\
\hline 1957 & -0.04 & 0.05 & -0.26 & $0.06^{* * *}$ \\
\hline 1962 & 0.12 & $0.05^{*}$ & 0.02 & 0.05 \\
\hline 1967 & 0.07 & 0.06 & 0.05 & 0.05 \\
\hline 1972 & -0.05 & 0.07 & 0.05 & 0.06 \\
\hline 1977 & 0.06 & 0.09 & -0.01 & 0.08 \\
\hline 1982 & 0.39 & $0.14^{* *}$ & -0.09 & 0.12 \\
\hline Intercept & 1.43 & $0.04^{* * *}$ & -0.55 & $0.03^{* * *}$ \\
\hline$N$ & \multicolumn{2}{|c|}{29,634} & \multicolumn{2}{|c|}{21,854} \\
\hline
\end{tabular}

${ }^{*} p \leq 0.05,{ }^{* *} p \leq 0.01,{ }^{* * *} p \leq 0.001$ (two-tailed test).

biblical literalists. The 1960s though early 1980s cohorts, however, are about as likely as pre-World War II cohorts to view the bible as the literal word of God. These results provide mixed support for theories that predict declines in biblical literalism (e.g. Smith, 1992). While biblical literalism declines somewhat across periods, there appears to be a moderate resurgence in biblical literalism among the youngest birth cohorts.

Conclusions

Differentiating between period and cohort effects has been a key impediment to estimating changes in religious belief and activity (Firebaugh and Harley, 1991). APC intrinsic estimator models overcome the linear dependency problem that plagues APC analyses. These models show that some key indicators of religion have declined while others are stable across periods and birth cohorts. The above findings lend support to Yang et al. (2008) assertion that APC intrinsic estimator models provide more accurate and theoretically appropriate results than other methods of simultaneously estimating APC effects. ${ }^{5}$ 

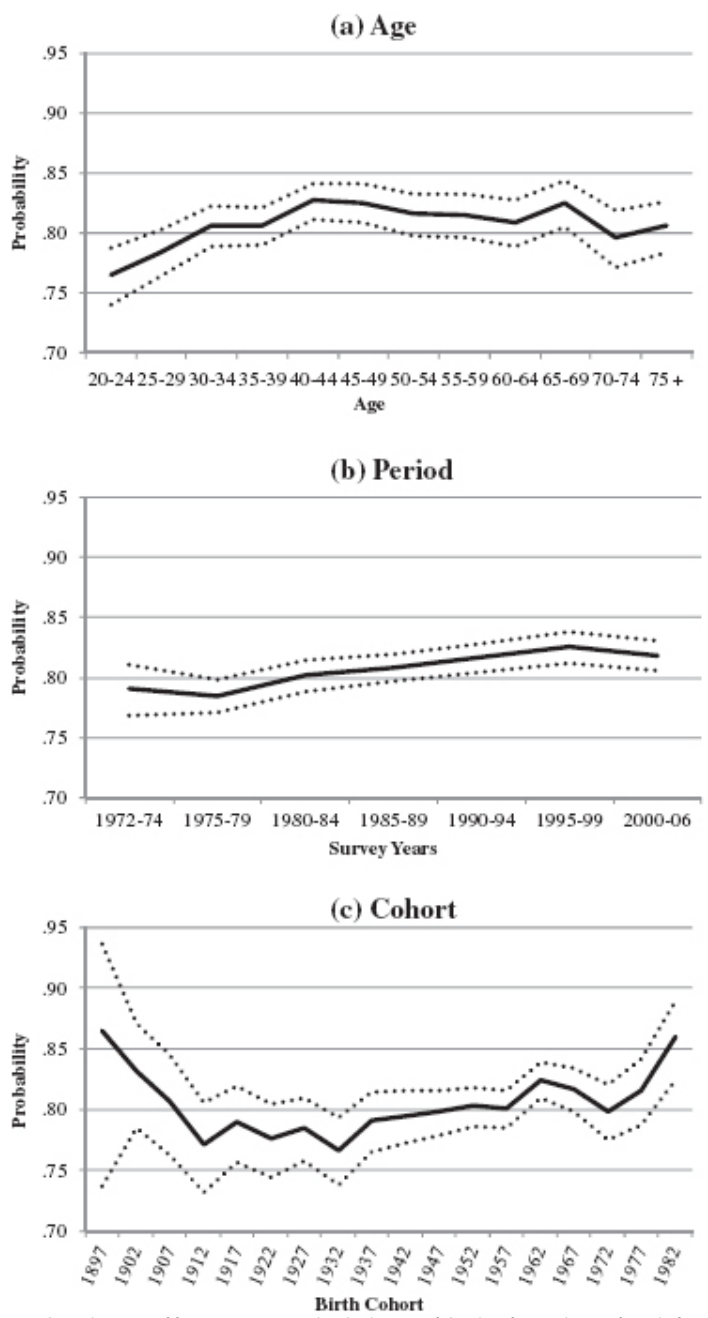

Figure 4. Estimated age, period, and cohort effects on probability of belief in the afterlife. Notes: Figure graphs results reported in Table 2; dashed lines represent 95 percent confidence intervals.

For instance, analysis of period and cohort changes in religious service attendance using cross-classified, random-effects APC models corroborate the above findings in regards to age and period effects (Schwadel, 2010b). That research, however, reports little cohort-based change in religious service attendance while the APC intrinsic estimator model suggests at least moderate across-cohort declines in attendance beginning with World War II cohorts. Unlike results from cross-classi.ed models of service attendance, APC intrinsic estimator results support theoretical expectations of a decline in religious participation across cohorts (Miller and Nakamura, 1996; Sasa$\mathrm{ki}$ and Suzuki, 1987). In addition to providing theoretically appropriate results, APC intrinsic estimator models have methodological advantages. Unlike most methods of simultaneously estimating APC effects, parameter constraints in intrinsic estimator models are unrelated to the substance of the research and decisions made by the researcher (Fu, 2008). Analyses of trends in religiosity generally make assumptions such as dropping age fromthe model to avoid the identification problem (e.g. Chaves, 1989), which can profoundly influence the results (Firebaugh and Harley, 1991). These types of assumptions are unnecessary when using APC intrinsic estimator models. Most importantly, APC intrinsic estimator results differ considerably from gross age, period, and cohort effects, which suggests that analyses of trends using repeated cross-sectional data that do not simultaneously estimate age, period, and cohort effects may provide misleading results. Overall, the APC intrinsic estimator is a methodologically appropriate and relatively accessible method for simultaneously estimating age, period, and

${ }^{1}$ Yang et al. (2008) use simulated data to demonstrate that intrinsic estimator models are less likely than other methods of estimating APC effects to detect non-existent period effects. 
(a) Age

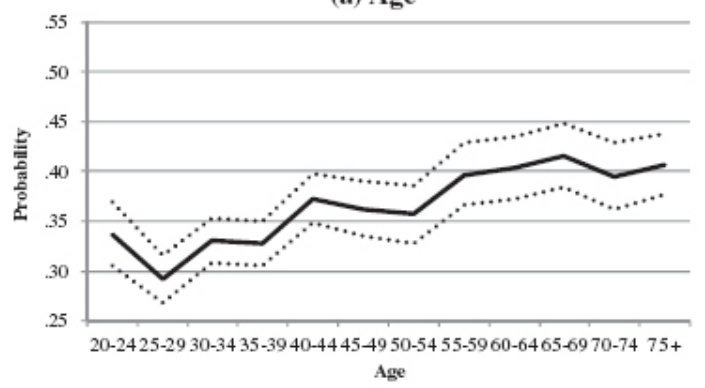

(b) Period

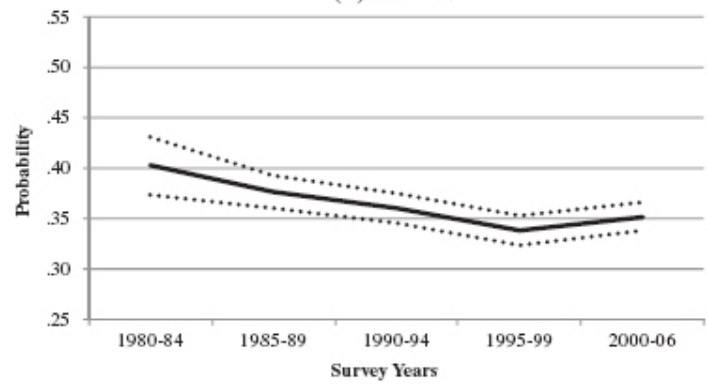

(c) Cohort

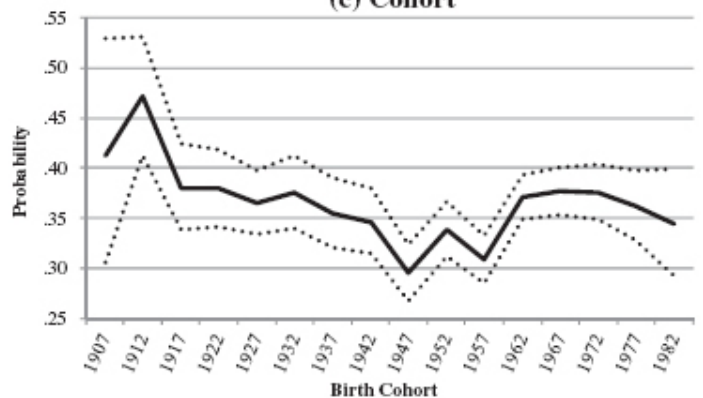

Figure 5. Estimated age, period, and cohort effects on probability of biblical literalism. Notes: Figure graphs results reported in Table 2; dashed lines represent 95 percent confidence intervals.

cohort effects, and the value of the model is further verified by the theoretically appropriate results.

The above results demonstrate the importance of simultaneously estimating age, period, and cohort effects when identifying time or cohort trends with repeated cross-sectional data. For instance, the large across-cohort declines in prayer, service attendance, and biblical literalism in the gross cohort effects models (Figure 1) are greatly diminished in the APC models (Figures 2,3, and 5). These results suggest that age influences cohort effects when age and cohort are not both included in the model. Similarly, important trends are masked if we look only at gross period effects. Although prayer is relatively stable in the gross period effects model (Figure 1), the APC model shows meaningful across-cohort declines in prayer (Figure 3). The size of baby boom cohorts coupled with the positive effect of age appears to be concealing a decline in frequency of prayer. While attendance declines across periods in the gross period model (Figure 1), the APC model shows that attendance is declining across cohorts far more than across periods (Figure 2). As Miller and Nakamura (1996) propose, across-cohort declines in religious service attendance and the positive effect of age suggest that the aging baby boom generation may be concealing a greater decline in attendance than the time trends show. Expectations of declines in religion are integral to many secularization theories and views of modernity (Swatos and Christiano, 1999). The above results provide mixed support for individual-level secularization theories. Regular religious service attendance declines moderately from the early 1970s to 2006, and this change is predominantly due to differences across cohorts. While there is no apparent decline over time in prayer as of yet, Americans born since the 1930s are less likely than those born before the 1930s to pray weekly. In other words, cohort replacement may soon lead to a 
decline in prayer. The secularization argument is also supported by a period-based decline in biblical literalism. On the other hand, belief in the afterlife is consistently high across periods and cohorts, and the youngest cohorts are more inclined towards biblical literalism than are the immediately post-World War II cohorts. These latter findings support views emphasizing the vitality of religion in contemporary American society, at least in terms of religious beliefs (e.g. Greeley, 1989; Greeley and Hout, 1999).

While the results provide mixed support for theories of religious decline, they suggest that baby boomers are particularly disconnected from religion. Americans born in the later 1940s and in the 1950s - the heart of the baby boom generation - are particularly unlikely to hold literal views of the bible. The across-cohort decline in attendance begins among baby boom cohorts. Additionally, the probability of weekly prayer is lowest among baby boom cohorts. In their analysis of religious disaffiliation, Hout and Fischer (2002) propose a 1960s legacy effect that leads to religious decline. The above results suggest that the 1960s legacy effect may be specific to those who matured in and around the 1960s, rather than enduring across later cohorts.

\section{References}

American Association for Public Opinion Research, 2008. Standard Definitions: Final Dispositions of Case Codes and Outcome Rates for Surveys, 5th ed. Lenexa, Kan.: AAPOR.

Carroll, Jackson W., Douglas W. Johnson, Martin E. Marty. 1979. Religion in America: 1950 to the Present. San Francisco: Harper \& Row.

Chaves, Mark. 1989. Secularization and religious revival: evidence from U.S. church attendance rates, 1972-1986. Journal for the Scientific Study of Religion 28: 464-477.

Chaves, Mark. 1991. Family structure and protestant church attendance: the sociological basis of cohort and age effects. Journal for the Scientific Study of Religion 30: 501-514. Chaves, Mark. 1994. Secularization as declining religious authority. Social Forces 72: 749-774.

Davis, James A., Tom W. Smith, and Peter V. Marsden. 2007. General Social Surveys, 1972-2006 [Cumulative File] [Computer File]. ICPSR04697-v1. National Opinion Research Center [producer], Chicago, Ill., 2007. Storrs, Conn.: Roper Center for Public Opinion Research, University of Connecticut/Ann Arbor, Mich.: Inter-university Consortium for Political and Social Research [distributors].

Dobbelaere, Karel. 1999. Towards an integrated perspective of the processes related to the descriptive concept of secularization. Sociology of Religion 60: 229-247.

Finke, Roger, and Rodney Stark. 1992. The Churching of America, 1776-1990. New Brunswick, N.J.: Rutgers University Press.

Firebaugh, Glenn. 1997. Analyzing Repeated Surveys. Thousand Oaks, Calif.: Sage.

Firebaugh, Glenn, and Brian Harley. 1991. Trends in U.S. church attendance: secularization and revival, or merely lifecycle effects? Journal for the Scientific Study of Religion 30: 487-500.

$\mathrm{Fu}$, Wenjiang J. 2000. Ridge estimator in singular design with application to age-period-cohort analysis of disease rates. Communication in Statistics - Theory and Methods 29: 263-278.

Fu, Wenjiang J. 2008. A smoothing cohort model in age period cohort analysis with applications to homicide arrest rates and lung cancer mortality rates. Sociological Methods \& Research 36: 327-361.

Glenn, Norval D. 2005. Cohort Analysis. Thousand Oaks, Calif.: Sage.

Greeley, Andrew M. 1989. Religious Change in America. Cambridge, Mass.: Harvard University Press.

Greeley, Andrew M., and Michael Hout. 1999. Americans' increasing belief in life after death: religious competition and acculturation. American Sociological Review 64: 813-835.

Hout, Michael, and Claude S. Fischer. 2002. Why more Americans have no religious preference: politics and generations. American Sociological Review 67: 165-190.

Hout, Michael, and Andrew M. Greeley. 1987. The center doesn't hold: church attendance in the United States, 1940-1984. American Sociological Review 52: 325-345.

Marsden, George M. 1991. Understanding Fundamentalism and Evangelicalism. Grand Rapids, Mich.: Eerdmans.

Miller, Alan S., and Takashi Nakamura. 1996. On the stability of church attendance patterns during a time of demographic change: 1965-1988. Journal for the Scientific Study of Religion 35: 275-284.

Norris, Pippa, and Ronald Inglehart. 2004. Sacred and Secular: Religion and Politics Worldwide. New York: Cambridge University Press.

Ploch, Donald R., and Donald W. Hastings. 1994. Graphic representations of church attendance using general social survey data. Journal for the Scientific Study of Religion 33: 16-33.

Roof, WadeClark, and William McKinney.1987. AmericanMainline Religion:Its Changing Shapeand Future. New Brunswick, N.J.:RutgersUniversity Press.

Ruiter, Stijn, and Frank van Tubergen. 2009. Religious attendance in cross-national perspective: a multilevel analysis of 60 countries. American Journal of Sociology 115: 863-895.

Ryder, Norman B. 1965. The cohort as a concept in the study of social change. American Sociological Review 30: 843-861.

Sasaki, Masamichi, and Tatsuzo Suzuki. 1987. Changes in religious commitment in the United States, Holland, and Japan. American Journal of Sociology 92: 1,055-1,076.

Schwadel, Philip. 2010a. Period and cohort effects on religious non-affiliation and religious disaffiliation: a research note. Journal for the Scientific Study of Religion 49: 311-319.

Schwadel, Philip. 2010b. Age, period, and cohort effects on U.S. religious service attendance: the declining impact of sex, southern residence, and Catholic affiliation. Sociology of Religion 71: 2-24.

Smith, Tom W. 1992. Are conservative churches growing? Review of Religious Research 33: 305-329.

Swatos, William H., and Kevin J. Christiano. 1999. Secularization theory: the course of a concept. Sociology of Religion 60: 209-228.

Voyé, Liliane. 1995. From institutional Catholicism to “Christian inspiration.” In: Wade Clark Roof, Jackson W. Carroll, and David A. Roozen (editors), The Post-War Generation and Establishment Religion: Cross-Cultural Perspectives. Boulder, Colo.: Westview Press, pp. 191-206.

Wilson, Bryan. 1982. Religion in Sociological Perspective. Oxford: Oxford University Press.

Wuthnow, Robert. 1976. Recent patterns of secularization: a problem of generations? American Sociological Review 41: 850-867.

Yang, Yang, Wenjiang J. Fu, and Kenneth C. Land. 2004. A methodological comparison of age-period-cohort models: the intrinsic estimator and conventional generalized linear models. Sociological Methodology 34: 75-110.

Yang, Yang, Sam Schulhofer-Wohl, Wenjiang J. Fu, and Kenneth C. Land. 2008. The intrinsic estimator for age-period-cohort analyses: what it is and how to use it. American Journal of Sociology 113: 1,697-1,736. 